Revista Iberoamericana, Vol. LXXVIII, Núms. 238-239, Enero-Junio 2012, 91-107

\title{
LA ERA DE LOS TECNOBEBÉS: JUAN JOSÉ ARREOLA Y EL MODELO CRÍTICO DE LA CIENCIA-FICCIÓN
}

\author{
POR \\ PABLO BRESCIA \\ University of South Florida
}

La ironía no es cosa de broma.

Friedrich Schlegel

Yo escribo para el lector que no me entenderá. Ese, para mí, es el lector ideal.

Juan José Arreola

En The Future of Human Nature (2003) Jürgen Habermas indica que tanto las doctrinas metafísicas como las humanistas tradicionales expresan un entendimiento de la naturaleza humana que es consistente con una moralidad autónoma. Sin embargo, dice el filósofo, tanto desde la ciencia ficción como desde las revistas científicas surge la idea de una instrumentalización que rompe las fronteras entre lo orgánico y lo artificial. Para Habermas, esto quiere decir que el entendimiento que los seres humanos tenemos de nuestra propia naturaleza cambia a tal punto que "we may no longer see ourselves as ethically free and morally equal beings guided by norms and reasons" (40-41). El escritor mexicano Juan José Arreola (1918-2001) publicó “Baby H.P.” en 1952. El cuento trata sobre un artefacto que funciona como depósito de energía cuando se coloca en la espalda de los niños. También, en el 2003, un artículo periodístico aparecido en The New York Times Magazine informaba sobre un invento similar al propuesto en el texto de Arreola destinado a patentarse en los Estados Unidos.

Conjuntando estas lecturas, propongo analizar desde la literatura algunos aspectos de lo que se ha dado en llamar la "condición tecnológica", ${ }^{1}$ contemplando tanto el

1 Utilizo este término basado en el libro Philosophy of Technology. The Technological Condition. An Anthology, ed. Robert C. Scharff y Val Dusek. Nuestro trabajo es una versión modificada y expandida de "Dos escritores y un bebé: ansiedades tecnológicas transamericanas", aparecido en Ficciones de los medios en la periferia. Técnicas de comunicación en la ficción hispanoamericana moderna. Ese ensayo obtuvo el Jamie Bishop Memorial Award for an Essay Not in English 2010 convocado por la International Association for the Fantastic in the Arts y logró una mención honorífica en el concurso de ensayo Premio 
horizonte sincrónico como el diacrónico. “Baby H.P.” ofrece un caso interesante no sólo para estudiar las representaciones y tensiones entre el aura simbólica de la tecnología, asociado casi indefectiblemente a la idea de progreso, y el imaginario humanista de los años cincuenta en Latinoamérica, sino también para indagar los efectos que la lectura de este texto (a la luz de Habermas y del artículo de The New York Times Magazine, por ejemplo) tiene en nuestra época. Para llevar a cabo esta tarea se hace necesario analizar los principales componentes del relato a partir, sugiero, de la tríada discurso (mercadotecnia publicitaria)-género (ciencia ficción)-tropo literario (ironía). En segundo término, es menester enfocar un aspecto que hasta ahora no se ha estudiado en profundidad, esto es, las cuestiones éticas que surgen detrás de la fachada humorística al relacionar el cuento con la condición tecnológica y el poshumanismo. Tomando en cuenta, por un lado, estudios pertinentes sobre la filosofía de la tecnología en general y sobre la relación entre la ciencia, la tecnología y la literatura en Latinoamérica en particular y, por el otro, la visión-expresión de Arreola, se trata de investigar en este caso cuáles son los modos críticos que la ciencia ficción plantea para leer la cultura en momentos históricos donde la ciencia es ficción y también en otros donde la ficción puede convertirse en ciencia.

\section{ESTRATEGIAS CRÍTICAS/CRÍTICAS DE LAS ESTRATEGIAS}

Arreola contribuyó a la renovación de la narrativa mexicana y latinoamericana a partir de Varia invención (1949) y Confabulario (1952). Los estudiosos de su obra han clasificado la diversidad de estas colecciones de cuento en cuatro áreas: el enfoque en las relaciones con la mujer; la preocupación por cuestiones teológicas y morales; la reflexión sobre el arte, la creación y la enseñanza y el cuestionamiento a las convenciones sociales y a la idea del progreso. Es allí donde generalmente se inserta “Baby H.P.”(Confabulario 144-45). Además de ser pedagógicamente dúctil y, por tanto, asiduamente utilizado por los manuales de literatura y de lengua, "Baby H.P.” forma parte de varias antologías de cuento mexicanas, latinoamericanas e internacionales. A pesar de esta ubicuidad, se ha hecho difícil identificar trabajos críticos dedicados exclusivamente a él. Los comentarios que lo mencionan, visto siempre a la luz del corpus narrativo del escritor mexicano, señalan el gusto de Arreola por las situaciones absurdas y el humor negro, el ingenioso formato que presenta el texto y la crítica a la sociedad de consumo representada por la compañía estadounidense (J. P. Mansfield \& Sons) que fabrica el producto. ${ }^{2}$

Internacional de Ciencia Ficción Julio Verne 2009 patrocinado por la Dirección General de Cultura del Ayuntamiento de Guadalajara, México, entre otras instituciones.

2 Las editoras de Cosmos Latinos hablan de un "sarcastic indictment of modern technology" en el cuento (Bell y Molina-Gavilán 58). Ana Belén Caravaca Hernández indica que "Baby H.P” "metamorfosea todos los ámbitos de lo social: la mirada del niño sobre su propio cuerpo y su cosmovisión, la estructura del

Revista Iberoamericana, Vol. LXXVIII, Núms. 238-239,
ISSN 0034-9631 (Impreso) 
El comienzo del relato sirve de muestra para el ángulo de interpretación elegido. "Señora ama de casa: convierta en fuerza motriz la vitalidad de sus niños. Ya tenemos en venta el maravilloso Baby H.P., un aparato que está llamado a revolucionar la economía hogareña” (144). A partir de este párrafo, pueden hacerse tres observaciones preliminares:

(1) El formato del texto se asemeja a un anuncio impreso, radial o televisivo. Como bien indica Salvador Gutiérrez Ordóñez, la publicidad se define por su orientación y finalidad perlocutiva según la teoría de los actos del habla de John Austin, es decir, la intención de influir sobre el destinatario para que actúe en determinado sentido, lo cual, en el caso de la publicidad comercial, tiene que ver con la compra y adquisición de bienes de consumo (7). Formalmente innovador para su tiempo, Arreola volvería a esta estrategia discursiva en "Anuncio" (1961), un relato sobre mujeres robóticas de marca "Plastisex" ${ }^{3}$ Lo que interesa destacar aquí es la naturaleza persuasiva de la mercadotecnia publicitaria, de la que Arreola claramente se apropia utilizándola como marco de su ficción. Si el propósito de un anuncio es informar sobre un producto y convencer al posible comprador de sus cualidades, “Baby H.P.” se inserta en este paradigma al intentar seducir al cliente mediante un aparato que mejorará la calidad y el confort de su vida.

(2) Este cuento puede ser ciertamente insertado dentro de la ciencia ficción. Una señal de su posible lectura en este contexto es, por ejemplo, su inclusión en la primera antología de textos hispánicos pertenecientes a este género en traducción, Cosmos Latinos: An Anthology of Science Fiction from Latin America and Spain (2003). Aquí nos basamos en dos definiciones del género. La primera, clásica, la ofrece Isaac Asimov en 1952: ${ }^{4}$ la ciencia ficción sería "that branch of literature which is concerned with the impact of scientific advance upon human beings”. La otra, de una gran riqueza conceptual, la provee Darko Suvin en 1979: "A literary genre whose necessary and sufficient conditions are the presence and interaction of estrangement and cognition, and whose main formal device is an imaginative framework alternative to the author's empirical environment” (Wolfe 109, 111). Más precisamente, "Baby H.P.” puede verse como un "gadget story", es decir, un relato que usa la ciencia para fundamentar la existencia de aparatos y de procesos técnicos. Estos textos por lo general se apoyan en un discurso científico imaginario, aunque no quita que algunos de sus supuestos se conviertan en

núcleo familiar, transformado en espacio de lucrativos negocios, y todas las conductas tradicionalmente establecidas" (64).

3 Habrá que trabajar sobre la presencia del discurso publicitario en la literatura latinoamericana. En Arreola, además de “Anuncio" (Confabulario 146-50), habría que pensar en "El fraude” (246-51). Un caso curioso e interesante es el cuento de Felisberto Hernández, "Muebles 'El canario'”. Agradezco este último dato a Ida Vitale.

4 Serendipia: 1952 no es sólo el año cuando se publica "Baby H.P” y Asimov ofrece su definición; es también la fecha de aparición de The Space Merchants, novela de Frederik Pohl y C. M. Kornbluth que toma lugar en Costa Rica y que critica la cultura del consumo capitalista. Agradezco a Libby Ginway este dato.

\footnotetext{
Revista Iberoamericana, Vol. LXXVIII, Núms. 238-239, Enero-Junio 2012, 91-107 ISSN 0034-9631 (Impreso) ISSN 2154-4794 (Electrónico)
} 
realidad (Lambourne et al 46). ${ }^{5}$ Volviendo al "extrañamiento cognitivo", este concepto aparece con frecuencia en los estudios sobre la ciencia ficción y refiere al efecto desfamiliarizador de un texto que, paradójicamente, está unido al mundo empírico por el efecto de realidad de sus detalles. Esta idea es útil, ya que por un lado liga el texto de Arreola con un tipo de ciencia ficción especulativa, es decir, una narración que funda mundos imaginarios sobre los existentes a partir de medios racionales o cognitivos, ${ }^{6} \mathrm{y}$, por otro lado, se relaciona con el recurso literario en el que se basa "Baby H.P" y este es:

(3) La ironía. En un nivel básico, puede definirse a la ironía como una discrepancia implícita entre lo que se dice y lo que se significa, entre el decir y lo dicho. No cabe abundar sobre las muchas ramificaciones del término. Por lo pronto, se favorece la etimología de la palabra: eironeia se refiere a "aquel que dice algo que no piensa en realidad" o a "aquel que cubre sus pensamientos con palabras". Para la propuesta de estas páginas, son provechosas las ideas de inversión semántica (cuando una palabra significa su opuesto) y de escamoteo. Esta dualidad inherente en la ironía es congruente con el concepto de lo familiar-que-se-desfamiliariza evocado por el extrañamiento cognitivo en la ciencia ficción. En el cuento de Arreola, la necesidad de una lectura irónica da por sentado un contexto cultural y una competencia de lectura específicas, digamos, de un receptor que habita en una sociedad con cierto desarrollo técnico y reconoce los pliegues narrativos y las convenciones de los anuncios mediáticos. Porque en verdad, como veremos, para que la ironía funcione en "Baby H.P” debemos leer el cuento contra el discurso mercadotécnico de la publicidad.

Desarrollemos las observaciones anteriores. En primer lugar, ¿cómo intenta persuadir "Baby H.P.”? Desde el comienzo establece un pacto de entendimiento con su público, las "amas de casa", en ese momento histórico la audiencia primordial a la que estaba destinada la publicidad sobre los aparatos domésticos. La mayoría de los anuncios que se ven por televisión en la actualidad, por ejemplo, nos enrostran: "Ud.... ¿̇está cansado de estar gordo?” $\mathrm{O}$, si lo adaptáramos a nuestro contexto, “Ud...., ¿ ¿no quisiera convertir la energía de su niño en algo provechoso?”. Este uso del "ud.” universal es clave para el discurso publicitario ya que tiene la fuerza perlocucionaria de establecer un pacto exclusivo y casi íntimo con la audiencia. El anuncio le habla a millones de personas, pero habla de tu problema. Por otra parte, la apelación a la utilidad del

5 Existen diferencias importantes entre la ciencia y la tecnología, más allá de la simple consideración de la tecnología como ciencia aplicada. Si bien es cierto que la ciencia tiende a los procesos de abstracción y experimentación (conocimiento teórico) mientras que la tecnología está más cerca de la fabricación y el uso de objetos y aparatos (conocimiento instrumental), esto no quita que, como indican Mark L. Greenberg y Lance Schachterle, “'technology' is an 'ology’, an intellectual discourse, a system” (15).

6 Para más información sobre el debate entre ciencia ficción dura vs. especulativa, cf. el número de mayo del 2004 de Publications of the Modern Language Association of America, Science Fiction and Literary Studies: The Next Millenium.

$\begin{array}{lllll}\text { ISSN 0034-9631 (Impreso) } & \text { ISSN 2154-4794 (Electrónico) }\end{array}$ 
producto - es decir, la conversión de algo que, aparentemente, no tiene valor de uso a algo que sí lo tendría- explota la expectativa común en sociedades de alto desarrollo técnico con respecto a la utilidad. Hasta aquí vemos a "Baby H.P.” como un anuncio. Pero la operación que realiza Arreola con este tipo de marco discursivo es compleja. Manuela Catalá Pérez indica que, aunque la publicidad valora la novedad, su discurso es conservador y se cuida de no transgredir demasiado. Es decir, se juega a romper las expectativas, pero de tal manera que no se aliene al receptor (132-33). Sólo podemos suponer cómo estaría conformado el eje pragmático para el momento del "anuncio" del Baby HP en 1952, pero no es aventurado arriesgar que sería demasiado transgresor si fuera literal (tal vez en el siglo xxi ya no sea tan así). Estamos ante un texto literario, y la persuasión cobra otro cariz.

Con respecto a la ciencia ficción, en el texto la única referencia específica a la ciencia se comunica de manera significativa: la energía del niño será transformada en "fuerza motriz" (144). La palabra fuerza ligada a un término técnico subraya el contexto científico, mientras que la asociación entre caballos de fuerza y bebés pone de manifiesto el aura de ficción en el texto de ciencia ficción, y produce el efecto irónico a partir del extrañamiento cognitivo del que hablábamos. ${ }^{7}$ Aquí aparece el sesgo crítico del género. Como aclara Caravaca Hernández, el relato instaura “una moral 'otra’ que socava la del mundo empírico, pero que terriblemente no anula la sospecha de que todo es realizable en una sociedad utilitaria y pragmática” (65). Desde un punto de vista exclusivamente técnico hay que aclarar que tal como Arreola describe la invención no sería posible, ya que la energía del niño es cinética -es decir, producida por un cuerpo en movimiento- y no estática -donde el objeto va adquiriendo cargas eléctricas. Las botellas de Leyden, inventadas hacia mediados del siglo xvIII, son dispositivos que funcionan como condensadores para almacenar energía estática. Arreola seguramente toma esta referencia de un manual escolar o de divulgación de física y su apropiación del asunto también puede verse como una señal del "atraso" tecnológico en América Latina. ${ }^{8}$ Por eso, el relato pone en escena de manera efectiva el extrañamiento cognitivo: la “ciencia” que presenta es, en el momento de su aparición, ficción, pero amenaza, bajo el manto del humor y la ironía, con pasar al plano de lo real. ${ }^{9}$

¿Cómo es, entonces, que funciona la ironía en “Baby H.P.”? Aquí es donde Arreola nos invita a contemplar su visión de mundo y las particularidades de su estilo. Con

7 Una muestra de la relevancia de los contextos de lectura para la interpretación de textos (y del poder de las marcas y de la publicidad) es la reacción de mis alumnos al estudiar “Baby H.P.” En su gran mayoría, asumen que "H.P.” refiere a Hewlett Packard.

8 Agradezco a Miguel de Asúa sus valiosas sugerencias en este punto.

9 Helena Calsamiglia comenta que el uso del discurso científico en la publicidad pone en funcionamiento "la divulgación (hacer saber) de técnicas nuevas debidas a los avances de la ciencia, al tiempo que se hace propaganda de su utilidad y de su papel en el futuro (hacer creer)”.

\footnotetext{
Revista Iberoamericana, Vol. LXXVIII, Núms. 238-239, Enero-Junio 2012, 91-107 ISSN 0034-9631 (Impreso) ISSN 2154-4794 (Electrónico)
} 
frecuencia redacta sus textos como si fuera un científico loco o, por lo menos, obsesivo, y lleva una idea hasta sus últimas consecuencias. Durante ese proceso, yuxtapone códigos culturales, sociales, literarios. En este texto en particular combina el formato del anuncio publicitario, el contexto tecno-científico y la ironía para darnos a beber un cocktail explosivo: la idea de que los niños pueden ser usados como herramientas para el progreso de la sociedad. La unión de dos términos, niño/ herramienta, que no se llevan bien juntos produce un efecto siniestro y de absurdo, pero no irracional. Como dice Ballart con respecto a ciertos usos de la ironía, "el prisma desde el que las cosas son vistas en el relato puede a veces reservar al lector una percepción de mundo tan chocante que la lectura irónica y distanciada sea la única recomendable” (400). En "Baby H.P.” casi inmediatamente cobra fuerza esa necesidad de la lectura irónica y experimentamos una sensación de eureka: ‘¡Ah! No quiere decir esto, quiere decir lo otro...' Donde el texto dice una cosa, está diciendo, también, lo contrario. El movimiento de lectura es antifrástico. En el lector recae la tarea de reconstruir semántica y pragmáticamente la intención significante del que emite el mensaje. ${ }^{10}$

Hay varias combinaciones del discurso de la publicidad mercadotécnica, la ciencia ficción y la ironía a lo largo del texto. La representación literaria del discurso publicitario logra replicar sus características: la descripción positiva del producto -Baby H.P. otorga "útiles segundos de tromba licuadora”; el usual desligamiento de responsabilidades de la compañía -los rumores sobre posibles electrocuciones son "completamente irresponsables" ya que no pueden ocurrir accidentes si se siguen las instrucciones- y el énfasis en la conveniencia -“El Baby H.P. está disponible en las buenas tiendas en distintos tamaños, modelos y precios” (145). Las referencias a la ciencia y a la tecnología se combinan con la tendencia que tiene Arreola de escribir a partir del "como si" de la filosofía y de la ciencia ficción. Por ejemplo, una ventaja impensada que tiene el invento es que mejora la autoestima de los niños, ayudándolos a establecer y superar sus propias marcas de acumulación energética. "Para este fin”, sigue el anuncio, "se recomiendan las golosinas azucaradas, que devuelven con creces su valor. Mientras más calorías se añadan a la dieta del niño, más kilovatios se economizan en el contador eléctrico" (145). La yuxtaposición de un lenguaje técnico -kilovatios, contador eléctrico- y el concepto de análisis de costo con el protagonismo de un bebé hace que el choque contra la creencia popular sea dramático. Cualquier padre ha experimentado en carne propia que los niños y el azúcar juntos dan dolores de cabeza. Al proponer al azúcar como una

${ }^{10}$ Dan Sperber y Deirdre Wilson examinan la función de la ironía y la distingue como un recurso metalingǘstico, porque siempre es mención, eco de otro enunciado; concluyen diciendo que "the attitude expressed by an ironical utterance is invariably of the rejecting or disapproving kind" y declarando que la ironía no difiere de enunciados no figurados y, por tanto, debe abandonarse su identificación como tropo (237-43).

Revista Iberoamericana, Vol. LXXVIII, Núms. 238-239,
ISSN 0034-9631 (Impreso) 
ventaja lograda por la innovación tecnológica, el cuento y el anuncio pierden credibilidad en el plano literal, convirtiéndose en utopías irrealizables. ¿̇ no?

\section{IDEOLOGÍAS TECNOLÓGICAS / TECNOLOGÍAS IDEOLÓGICAS}

En el caso de "Baby H.P”, el cruce de discurso publicitario, ciencia ficción e ironía revela una condición que proponemos denominar “ansiedad de progreso" y que afectó a varios escritores latinoamericanos en los años cincuenta. En una región que se ha descrito como simultáneamente pre-moderna, moderna y pos-moderna, los artistas se sentían atraídos y repelidos hacia las innovaciones científicas y técnicas de la modernidad. Hacia fines de siglo XIX, dice Julio Ramos, la literatura "comienza a definirse como una ambigua crítica de la racionalización; como defensa, frecuentemente, de los valores ‘humanos' e 'individuales' en un mundo en vías de tecnologización y masificación” (158). Para el momento de "Baby H.P.” esa óptica sigue siendo válida y Arreola, dentro de su desencanto humanista, participa de ella. ${ }^{11}$ En el contexto de México, si bien Rubén Gallo ha demostrado el llamado de la utopía tecnológica en algunos artistas mexicanos en las primeras décadas del siglo xx, varios de ellos también mostraban recelo ante un posible avance totalizador de la técnica. ${ }^{12}$ Es en los años del gobierno de Miguel Alemán (1946-1952) cuando ocurre el mayor desarrollo del llamado milagro mexicano, con una fuerte inversión e intervención política en infraestructura industrial que lleva a la transformación modernizadora del país.

Aesta ansiedad se agregaría lo que podríamos denominar la “ansiedad del capitalismo" que refiere más específicamente a los abusos de una tecnología en continua búsqueda del superávit comercial, dentro de un sistema totalizante de prácticas culturales que tienden al consumo de bienes materiales. Este sistema aparece frecuentemente representado por el pujante desarrollo económico e industrial de los Estados Unidos a partir de la Segunda Guerra Mundial. Es imposible no pensar en este contexto cuando el cuento

11 En una entrevista con Cristina Peri-Rossi, Arreola comenta: "Experimenté - experimento- el desencanto de una generación que conoció dos guerras -la Española y la Mundial-y sentí un profundo desencanto. Años de civilización y cultura, de arte y de ciencia no pudieron impedir catástrofes semejantes; ni el cristianismo, ni la técnica, ni la ciencia, habían servido, pues, para protegernos de la devastación y del genocidio" (24).

12 "During the two decades following the end of the revolution in 1920, Mexico modernized at a dizzying speed. The government ... built roads -it planned a network of highways 'traversing the nation from ocean to ocean and from border to border'- paved city streets and set out to completely rebuild a nation devastated by a decade of civil war”, dice Gallo (22). Como contrapartida, cf. los conceptos de Jaime Torres Bodet y Bernardo Ortiz de Montellano en el manifiesto de la revista La Falange: "Se vuelven [los que hacen la revista] a ellos [los países latinos] porque el excesivo progreso industrial y mecánico a que han llegado los pueblos sajones los han postergado [...]” (318).

\footnotetext{
Revista Iberoamericana, Vol. LXXVIII, Núms. 238-239, Enero-Junio 2012, 91-107 ISSN 0034-9631 (Impreso) 
de Arreola expresa que "las familias numerosas pueden satisfacer todas sus demandas de electricidad instalando un Baby H.P. en cada uno de sus vástagos, y hasta realizar un pequeño y lucrativo negocio, transmitiendo a los vecinos un poco de la energía sobrante” (144). Es aquí también donde se utiliza el marco de la ciencia ficción como arma crítica para censurar ciertos elementos presentes en sistemas económicos, políticos y sociales que conciernen, como quería Asimov, al avance científico y su influjo en los seres humanos. Es claro que, aunque en principio el invento puede no ser tan maligno, y hasta resultar beneficioso, la lectura irónica revela los peligros de una proposición como ésta en una sociedad abocada a las ganancias y el consumo.

Estas ansiedades que trasunta el cuento deArreola pueden aplicarse también a Estados Unidos y Europa, por supuesto. Pero no parecen ser del mismo tipo. ¿Cuáles serían las diferencias en la manera de percibir la función de la tecnología en Latinoamérica y en Estados Unidos, por ejemplo? Jane Robinett puntualiza que muchos ciudadanos latinoamericanos ven la tecnología como algo impuesto desde fuera y notan una gran distancia entre los usos de la tecnología y la gente que tiene poder de decisión sobre ellos (256) ${ }^{13}$ Aquí cabe recordar la obra de teatro de Karel Capek R.U.R. (Rossum's Universal Robots), de donde deriva la palabra "robot”. Como dice Michael Phillips, este texto demuestra que "under capitalism, market considerations determine what technologies are developed and employed. And in general, technologies are developed and employed in response to the need and desires of persons and organizations with wealth and power" (299).

Términos como eficiencia, velocidad, regularidad, planeación, control, estandarización -en su mayor parte provenientes del uso de la tecnología- se han ido incorporando a la cultura y al lenguaje cotidianos. En un momento, pudieron sentirse foráneos en Latinoamérica, y por eso la necesidad de crítica y vigilancia aparenta ser más urgente (Robinett 257). Sin embargo, nos parece correcta la apreciación de Jerry Hoeg cuando afirma que la posibilidad de volverle la espalda a la enmarcación (Gestell, en terminología de Heidegger) que conlleva la tecnología, "does not imply the archaic fallacy of a surmounting of technics through a return to a prelapsarian

${ }^{13}$ El libro de Robinett contiene algunas afirmaciones valiosas sobre la relación entre tecnología, magia y literatura en América Latina, pero muestra una visión parcial de la función de la tecnología (las novelas analizadas se parecen entre sí) y comete errores importantes, como afirmar que el realismo mágico y lo real maravilloso son lo mismo (19). Enrique Dussel afirma que las preguntas sobre la tecnología en el contexto latinoamericano tienen que ver con la opción entre el cambio en la infraestructura política y económica o el desarrollo tecnológico, ambas ligadas a las necesidades básicas de la población (Philosophy and Technology 103). En el mismo volumen, Margarita M. Peña Borrero indica que las decisiones sobre la tecnología deben ser políticas y no técnicas, "and the capacity of a country to make such decisions depends partly on its potential to assimilate critically the processes of technological development which take place beyond its borders” (285). Quizás este libro provea una plataforma adecuada para estudios comparativos.

Revista Iberoamericana, Vol. LXXVIII, Núms. 238-239,
ISSN 0034-9631 (Impreso) 
techno-inocence, but rather a surmounting of our relation with them through a new coding of the relationship between nature, society and technics” (22-23). La pregunta es precisamente cuáles serían los elementos que conformarían este nuevo código en diferentes circunstancias históricas, y en este contexto hay que subrayar que cuando se evalúa un nuevo invento-producto las determinaciones sobre ventajas y desventajas se basan en análisis binarios de costo-beneficio y riesgo-beneficio. Para Frederick Ferré, "a bias in favor of the measurable and marketable is built into the approach" (81). La interrogación de Arreola cuestiona y critica, mediante un dispositivo complejo, los valores de una sociedad futura que dependa de la tecnología.

\section{TU FICCIÓN ES MI REALIDAD}

Si como indica Catherine Kerbrat Orecchioni la ironía es, en su nivel más básico, hacer una broma, descalificar o burlarse de alguien, ¿por qué no aceptar que "Baby H.P” es una broma elaborada, obviamente con un sesgo crítico y un tanto perversa, pero igualmente evocadora de una sonrisa balsámica que nos retorna de los confines de la ciencia ficción a una realidad donde no existen los tecnobebés? Porque quizá el remate de estas bromas no sea tan gracioso como suponemos.

Aquí está la última pieza, por ahora, del rompecabezas. Desde el año 2001 The New York Times Magazine publica un número especial titulado "Las Ideas del Año" que comenta sobre las últimas novedades en grandes y pequeñas ideas. El 14 de diciembre del 2003 y bajo el subtítulo "Kid Power” ("El poder de los niños” o "Energía infantil”) se dio noticia de una invención de un profesor de ingeniería y ciencias de la computación en la Universidad de Tulane, Raj Pandian. Este invento almacena la energía de los niños en pequeños tanques y luego la convierte en electricidad que se acumula en pilas. ${ }^{14}$

Estos son los puntos salientes del artículo. La mayoría de las personas se preguntan sobre los niños, “¿¿de dónde sacan toda esa energía?”, mientras que Pandian se preguntó: “cómo puedo convertir esa energía en otro tipo de energía?” Demostró su invento en los subibajas, pero se adapta a calesitas y columpios; media hora de subibaja generaría electricidad suficiente para operar una computadora portátil entre veinte y cuarenta minutos. Pandian considera su invento como una fuente limpia y confiable de energía y está usando a su propio hijo en sus experimentos. La gran diferencia entre este artículo y el texto de Arreola es, obviamente, que este último es ficción, mientras que el artículo reporta una realidad ya que el invento estaba siendo patentado en el momento de la aparición del artículo (el sitio en la red de Pandian informa que recibió la patente en el año 2006, "Pneumatic human power conversion system based on children’s play",

${ }^{14}$ Este invento sugiere una comparación con la trilogía cinematográfica The Matrix, que imagina un mundo donde los seres humanos son baterías que alimentan a computadoras.

$\begin{array}{llllll}\text { ISSN 0034-9631 (Impreso) } & \text { ISSN 2154-4794 (Electrónico) }\end{array}$ 
U.S. Patent No. 7,005,757). Pandian no coloca el aparato en el cuerpo del niño (pero usa la energía emitida por ese cuerpo), mientras que Arreola sí lo hace. Salvada esta diferencia, las semejanzas son asombrosas.

Como si estuviéramos en Tlön, la ficción casi se ha transformado en realidad. Al leer este artículo nuestra incredulidad no recaía sobre el invento, sino sobre el hecho de que la idea de Arreola, diseñada literariamente como una mirada humorística sobre los posibles excesos de la tecnología y los efectos adormecedores de la publicidad, se había hecho realidad. ${ }^{15}$ El marco de referencia y de recepción ha cambiado y, cincuenta y ocho años después de "Baby H.P.”, nos preguntamos: ¿Existe ironía en el artículo periodístico? ¿Un significado más allá del texto, un sentido que el lector debe decodificar? Por lo pronto, no se ha propuesto ninguna lectura irónica; sólo existe el sentido literal. Si sólo existe ese sentido, alivia saber que la propuesta que hiciera Jonathan Swift en 1729, donde se proponía la canibalización de los niños como alternativa contra el hambre, no se concretó. La aplicación de las tres dimensiones actuales de la ciencia ficción a este invento de Pandian arrojaría resultados dispares. Los creyentes en la utopía lo celebrarían y se entusiasmarían con las posibilidades de mejorar las políticas energéticas; los partidarios de la "nueva ola" serían cuidadosos y preferirían trabajar sobre nuestro mundo actual tratando de regular el invento y los integrantes del grupo de la fantasía se mostrarían desesperados al ver una muestra más de la inexorable perdición del mundo y se retirarían a sus tierras imaginarias (Bainbridge 220).

Traigamos a colación "Baby H.P" a la luz de este artículo y al debate sobre la naturaleza humana que planteaba Habermas. Una pregunta clave en el contexto de fricción entre tecnología y naturaleza humana es por qué el paradigma utilitario parece imperar siempre en cuestiones de avance técnico. Habría que preguntarse: ¿utilidad para qué o para quién? De lo anterior surge un interrogante: en este contexto, ¿los niños son una molestia? Para Pandian, son un medio para un fin (es una visión instrumentalista de la tecnología que asume sólo las consecuencias benéficas de la misma); en el cuento de Arreola, nótese el lenguaje, hay un énfasis en la conversión del "agobiante ajetreo de sus hijos” y de sus "rabieta[s] convulsiva[s]” en energía útil (144). El filo crítico de la ironía no sólo pone en cuestionamiento por inferencia los avances indiscriminados de la técnica, sino también la estructura de la "felicidad” familiar. ${ }^{16}$ Habría que mencionar una cuestión

15 Aunque su escritura tenga rasgos satíricos, Arreola se sitúa más cerca de la parodia y la ironía en tanto recursos literarios efectivos para desestabilizar las estructuras y convenciones aceptadas. Como bien indica Martha Elena Munguía Zatarain, el autor satírico se "enuncia fuera del mundo referido" para entonces "ridiculizar usos y costumbres". En cambio, los textos de Arreola "están construidos en un espíritu de participación con los otros” (26). Por su parte, George Schade, en el prólogo a su traducción del Confabulario, define a Arreola como "an accomplished satirist" (viii).

${ }^{16}$ Para otro trabajo quedan posibles cruces intertextuales y culturales con cuentos más recientes como "I Can Speak! TM", de George Saunders, texto que trata de una máscara que "responds to aural patterns in a way that makes baby seem older” (3) y “Conversaciones con Yoni Rei”, del escritor de ciencia ficción

$\begin{array}{lllll}\text { ISSN 0034-9631 (Impreso) } & \text { ISSN 2154-4794 (Electrónico) }\end{array}$ 
más urgente tal vez: ¿quién regula la labor de los niños? ¿Cuándo pasamos de juego a trabajo? ¿Cuáles son los principios éticos que nos permiten hacer la distinción? Según el texto de Arreola, los niños deben usar el arnés todo el día e inclusive en la escuela, "para que no se pierdan las horas preciosas del recreo, de las que ellos vuelven con el acumulador rebosante de energía” (145). Increíblemente, Pandian dice que la energía en cuestión es gratis, y parece implicar que cualquiera puede apoderarse de ella. ¡Planea instalar el aparato en los patios de las escuelas! En ambos textos, la equivalencia entre juego y productividad es presupuesta, aunque con objetivos muy distintos. En cuanto al asunto de la utilidad, está claro que la urgencia ética está del lado del escritor mexicano.

Todas estas cuestiones merecen un desarrollo ulterior. El tema sobre el que interesa ahondar aquí es el del cuerpo como sitio para la experimentación, ya no sólo en la ciencia ficción, ligado a conceptos como naturaleza humana, subjetividad e identidad y, finalmente, ética. Desde hace décadas ha habido un debate continuo sobre los cyborgs, los tecnocuerpos y lo poshumano; las ideas de Donna Haraway, creadora del manifiesto cyborg en 1985, se refieren a la integración de sistemas naturales y artificiales: "the cyborg is our ontology; it gives us our politics”. Haraway hace del cyborg un mito que destruye los sistemas binarios de Occidente y lo imagina útil para la emancipación feminista, pero lo que resalta de su postura para nuestro análisis es que la imagen del cyborg esté relacionada a la ironía; se trata de "contradictions that do not resolve into larger wholes...” y continúa: "Irony is about humour and serious play. It is also a rhetorical strategy and a political method..." (429-30). La ironía como un recurso discursivo de fuerte sustrato ético-social en el contexto de la tecnología pone en juego el tema de la subjetividad y de la identidad entroncado al cuerpo. Quizás no es tan evidente en la invención de Pandian, aunque muchos verían los tanques como extensiones del cuerpo humano, pero si consideramos al Baby H. P. como una especie de cyborg rudimentario, el primer “tecnobebé” latinoamericano, este tema está más que presente en el texto: ¿"Pedrito” es el mismo con y sin la botella en su cuerpo? ¿Cambia su naturaleza al tener puesto el aparato que "se adapta con perfección al delicado cuerpo infantil, mediante cómodos cinturones, pulseras, anillos y broches” (144)? ${ }^{17}$

El trabajo, más cercano a la literatura, de Katherine Hayles sobre lo poshumano también resulta pertinente. Su definición de lo poshumano -“[i]n the posthuman, there

mexicano Juan José Rojo Solís (Pepe Rojo), una especie de "Baby H.P.” para nuestro siglo xxi. Del cuento de Saunders me ocupo en "Dos escritores y un bebé: ansiedades tecnológicas transamericanas” y en la antología donde se encuentra el relato de Rojo aparece "En verdad os digo”, de Arreola.

17 Jennifer L. Croissant señala que en las teorías del desarrollo motriz los cuerpos infantiles se conciben flexibles y capaces de ser programados para el ambiente y las distintas actividades. "Flexible bodies are tolerant and 'unresisting' in the sense of loosely bounded and not rigid” (286-87). Aunque provienen de un libro de divulgación, son altamente informativos los capítulos “Cyborgs corporativos e institucionales” (que trata de los cyborgs como máquinas de guerra) y “Neodarwinismo, bebés cyborg y eugenesia” en Yehya.

\footnotetext{
Revista Iberoamericana, Vol. LXXVIII, Núms. 238-239, Enero-Junio 2012, 91-107 ISSN 0034-9631 (Impreso) ISSN 2154-4794 (Electrónico)
} 
are no essential differences or absolute demarcations between bodily existence and computer simulation, cybernetic mechanism and biological organism, robot teleology and human goals" (3)- se relaciona con las preocupaciones de Habermas con las que comenzamos este trabajo. The Future of Human Nature sólo menciona de pasada a los cyborgs; su preocupación son las consecuencias de la ingeniería genética y lo que Habermas llama “eugenesia liberal” (otra cuestión urgente: las tecnologías reproductivas). En tanto, Hayles reivindica la deconstrucción del sujeto liberal que plantea lo poshumano, pero también admite que el concepto implica una rearticulación de las características asociadas a él: "agency and choice” (5). Habermas acude al imperativo moral kantiano para volver a hablar de la humanidad de manera más colectiva y menos individual. Pero, en diferentes contextos, tanto en 1952, como en el 2003, como hoy -tú, lector/cyborg que me lees- a causa de los avances tecnológicos, el concepto mismo de humanidad está en constante fluctuación.

No hay dudas que la tecnología ha afectado ese concepto; estamos en la etapa del examen de las consecuencias. Mark Poster, refutando un tanto la perspectiva de Martin Heidegger y apelando a los conceptos de Félix Guattari sobre las máquinas heterogenéticas, indica: "The question concerning technology, then, is no mere exercise about the destruction of nature by the irresponsible deployment of machines, or the loss of human reality into machines, o even the cultural "misshaping" of the human by its descent into the instrumental... Instead, the question of technology is now one of the nature of the cyborg, of the new order of humachines" (16). Pero hay otras perspectivas, como la Joanna Zylinska, quien arguye que no debemos necesariamente aceptar un modelo donde el organismo poshumano cibernético es la próxima etapa en la evolución de la humanidad; tanto la naturaleza como la tecnología tienen como impulso central abrirse al exterior y eso obliga "a rethinking of the ethical relationship between the self and its others” (216-17). Este creciente énfasis en la ética aparece también en el trabajo de Sherryl Vint, quien se aleja de las concepciones de un sujeto puramente material o puramente abstracto; para Vint, en el contexto de lo poshumano, "it is important to return to the notion of embodied subjectivity in order to articulate the ethical implications of technologies of bodily modifications” (8). ${ }^{18}$

\footnotetext{
${ }^{18}$ Estos diferentes posicionamientos sobre los efectos de la tecnología tiene su eco en la función y los usos de la tecnología vistos desde la filosofía. El material es muy amplio y la división entre "tecnófobos” y "tecnófilos" no hace justicia a la riqueza del debate, centrado en las tensiones que suscita definir el carácter de la tecnología y los mecanismos de decisión en el campo. Del imperdible volumen Philosophy of Technology. The Technological Condition, además de los artículos citados en este trabajo, se recomiendan los ensayos de Kristin Shrader-Frechette, Carl Mitcham, Langdon Winner, Emmanuel G. Mesthene y Andrew Feenberg. Un indicador de la creciente preocupación sobre la ética es el volumen Technology and Responsibility, ed. Paul T. Durbin.
}

Revista Iberoamericana, Vol. LXXVIII, Núms. 238-239,
ISSN 0034-9631 (Impreso) 
PolíticAs DEL ZOOLÓGico

Para una gran parte de la población de nuestro planeta, la tecnología media nuestra existencia. ¿Estamos de acuerdo con Yehya cuando comenta: “De todas las fantasías y las pesadillas que -imaginábamos- nos aguardaban en el año 2000 una, ciertamente, se ha cumplido: la humanidad es una especie en extinción. En su lugar, la sociedad telemática o posthumana se redefine diariamente mediante la alta tecnología y poco a poco se materializa la posibilidad la de crear vida inteligente no biológica” (11)? ¿O con lo que declara John Paul Russo?:

The humanities cannot bear the burden of value, guidance, and encouragement once placed upon them, existing as they do increasingly within a vacuum and receiving little help from the cultural environment. Technique has taken charge, setting parameters, directing choices, serving as inspiration-technique that includes medical breakthroughs, but also entertainment, propaganda, advertising, and global lifestyles. (22)

Estos dos ejemplos del debate demuestran la relevancia de la condición tecnológica.

En su ya clásico ensayo “La cuestión de la tecnología”, de 1954, Heidegger sostiene que la tecnología debe ser entendida desde la relación de los seres humanos con el mundo y la define, en su esencia, no como un medio sino como un modo de revelación ontológica cuyo rasgo esencial es la enmarcación (Gestell). Si no podemos pensar fuera de la tecnología, aduce Heidegger, no podemos tener una relación libre con ella. Tanto Heidegger como José Ortega y Gasset -en “Meditación de la técnica” (5: 317-75) y en "El mito del hombre allende a la técnica” (9: 617-24)- relacionan el techne con la necesidad de producción, de creación humana, ligada a poiesis para Heidegger y al bien-estar para Ortega y Gasset; nuestra relación con la tecnología cambia de acuerdo a estas conexiones. ¿Pero qué pasa cuando la naturaleza humana se instrumentaliza? Hans Jonas se preguntaba en 1979, pensando sobre todo en los avances de la genética y la biología: “Are we perhaps, on the verge of a technology [...] which, this time, has man himself for its object?” Más adelante indica: “One part of the ethics of technology is precisely to guard the space in which any ethics can operate” $(199,203)$. Más de treinta años después -y tal vez veintitrés años antes, en Arreola- la preocupación es similar para Habermas: "[I]f biotechnology is subtly undermining our identity as members of a species, should we want to be moral? [...] Life in a moral void [...] would not be worth living” (73).

Con su breve texto, Arreola persuade a los lectores de que tomemos en cuenta la recepción, el canal de difusión y la función que trabaja sobre lo artístico del lenguaje al leer “Baby H.P.”. Hay un distanciamiento, una inadecuación, que nos revela significados potenciales. Muchos años después, y frente a nuevas lecturas y teorizaciones, el texto

\footnotetext{
Revista Iberoamericana, Vol. LXXVIII, Núms. 238-239, Enero-Junio 2012, 91-107 ISSN 0034-9631 (Impreso) 
sigue buscando al receptor "re-activo" (Catalá Pérez 139). Disfrazado en el discurso publicitario, ${ }^{19}$ arropado en el modelo crítico de la ciencia ficción, Arreola nos lleva por la ironía a una segunda lectura, crítica de aquello mismo que se está "vendiendo", para que la dimensión ética asome en aquel lector que no lo entenderá, pero acabará entendiendo.

¿La humanidad evoluciona o se extingue, o estamos hablando de sinónimos? De cualquier modo y si nos convertimos en guardianes de nosotros mismos en un zoológico donde una especie -la humana- está mutando aceleradamente, podemos pensar en la literatura como una de las maneras de preservar los espacios éticos desde donde pensar y debatir la tecnología. Los Baby H.P. estarían de acuerdo. Habermas también y hasta se podría convencer a Pandian. Seguramente Arreola sonreiría.

\section{BiBLIOGRAFÍA}

Arreola, Juan José. Confabulario. México: Fondo de Cultura Económica, 1966.

Bainbridge, William Sims. Dimensions of Science Fiction. Cambridge: Harvard UP, 1986.

Ballart, Pere. Eironeia. La figuración irónica en el discurso literario moderno. Valencia: Sirmio, 1994.

Barr, Marleen S. y Carl Freedman, coords. Science Fiction and Literary Studies: The Next Millennium. Tomo especial de PMLA 119/3 (2004): 492-526.

Bell, Andrea I. y Yolanda Molina-Gavilán, eds. Cosmos Latinos: An Anthology of Science Fiction from Latin America and Spain. Middletown: Wesleyan UP, 2003.

Brescia, Pablo. "Dos escritores y un bebé: ansiedades tecnológicas transamericanas". Ficciones de los medios en la periferia. Técnicas de comunicación en la ficción hispanoamericana moderna. Actas del Coloquio Internacional de Colonia, 18-21 sept. 2007. Wolfram Nitsch, Matei Chihaia and Alejandra Torres, eds. Universitäts-und Stadtbibliothek Koeln. <http://www.uni-koeln.de/phil-fak/roman/home/ficciones/ ficciones.html>. 1 dic. 2009.

Calsamiglia, Helena. "Crónica de una ciencia anunciada. Reflexiones sobre el nuevo discurso publicitario de las empresas biotecnológicas”. Quark: ciencia, medicina y cultura 12 (1998). <http://www.prbb.org/quark/12/012019.htm>. 1 dic. 2009.

\footnotetext{
19 Tanto desde la filosofía de la tecnología como desde los estudios de la publicidad se advierte sobre la necesidad de vigilancia con respecto al tema. Jacques Ellul, proponente de la autonomía de la tecnología, señala que "the technological system contains its own technological power of legitimation, advertising ... Advertising is a technology, indispensable to technological growth and meant to supply the system with its legitimacy” (395-396), mientras que Antonio Caro Almela es categórico: “... la elaboración de productos que satisfacen necesidades ha sido sustituida por la construcción de marcas que generan su propia necesidad, la publicidad pasa a ser una ideología fría, subrepticia, irrebatible y placentera que está conduciendo a la humanidad -si nadie lo remedia- a la gran catástrofe ecológica, de la cual la presente crisis capitalista constituye probablemente su primer síntoma” (103)
}

\footnotetext{
Sevista Iberoamericana, Vol. LXXVIII, Núms. 238-239, Enero-Junio 2012, 91-107 ISSN 0034-9631 (Impreso) $\quad$ ISSN 2154-4794 (Electrónico)
} 
Caravaca Hernández, Ana Belén. Juan José Arreola: fragmentos de una escritura trucada. Valencia: Tirant lo Blanch Libros, 1998.

Caro Almela, Antonio. "La publicidad como dispositivo operacional". Pensar la Publicidad 2/2 (2008): 81-106.

Catalá Pérez, Manuela. "Ironía, humor e inferencia: procesos cognitivos. Tendencias creativas en la publicidad actual”. Acciones e investigaciones sociales 12 (2001): $130-42$.

Croissant, Jennifer. "Growing Up Cyborg. Development Stories for Postmodern Children”. Cyborg Babies. From Techno-Sex to Techno-Tots. Robbie Davis-Floyd and Joseph Dumit, eds. New York: Routdlege, 1998. 285-300.

Durbin, Paul T., ed. Technology and Responsability. Dordrecht: D. Reidel, 1987.

Dussel, Enrique. "Technology and Basic Needs: Proposal for a Debate on Fundamental Criteria”. Philosophy of Technology in Spanish Speaking Countries. Carl Mitcham, ed. Dordrecht: Kluwer Academic Publishers, 1993.

Ellul, Jacques. “The 'Autonomy' of the Technological Phenomenon”. Philosophy of Technology. The Technological Condition. Robert C. Scharff and Val Dusek, eds. Malden: Blackwell Publishing, 2003. 386-97.

Ferré, Frederick. Philosophy of Technology. New Jersey: Prentice Hall, 1988.

Gallo, Rubén. Mexican Modernity: The Avant-Garde and The Technological Revolution. Boston: MIT P, 2005.

Greenberg, Mark L. y Lance Schachterle, eds. Literature and Technology. Bethlehem: Lehigh UP, 1992.

Gutiérrez Ordóñez, Salvador. Comentario pragmático de textos publicitarios. Madrid: Arco Libros, 2000.

Habermas, Jürgen. The Future of Human Nature. Cambridge, England: Polity Press, 2003.

Haraway, Donna. “A Cyborg Manifesto: Science, Technology, and Socialist-Feminism in the Late Twentieth Century". Philosophy of Technology. The Technological Condition. Robert C. Scharff y Val Dusek, eds. Malden: Blackwell Publishing, 2003. 429-50.

Hayles, N. Katherine. How We Became Posthuman. Virtual Bodies in Cybernetics, Literature and Informatics. Chicago: U of Chicago P, 1999.

Heidegger, Martin. “The Question Concerning Technology”. Philosophy of Technology. The Technological Condition. Robert C. Scharff y Val Dusek, eds. Malden: Blackwell Publishing, 2003. 252-64.

Hernández, Felisberto. “Muebles ‘El Canario””. Obras completas. 8a. ed. Vol. 2. México: Siglo XXI, 2007. 156-59.

Hoeg, Jerry. Science, Technology and Latin American Narrative, in the Twentieth Century and Beyond. Bethlehem: Lehigh UP, 2000.

\footnotetext{
Revista Iberoamericana, Vol. LXXVIII, Núms. 238-239, Enero-Junio 2012, 91-107 ISSN 0034-9631 (Impreso) 
Jonas, Hans. "Toward a Philosophy of Technology”. Philosophy of Technology. The Technological Condition. Robert C. Scharff y Val Dusek, eds. Malden: Blackwell Publishing, 2003. 191-204.

Kerbrat Orecchioni, Catherine. "La ironía como tropo". De la ironía a lo grotesco (en algunos textos literarios hispanoamericanos). [1980]. México: Universidad Autónoma Metropolitana-Iztapalapa, 1992. 195-221.

“Kid Power”. The New York Times Magazine. 14 dic. 2003: 80.

Lambourne, Robert, et al. Close Encounters? Science and Science Fiction. Bristol: Adam Hilger, 1990.

Peri-Rossi, Cristina. “'Yo, señores, soy de Zapotlán el grande’: entrevista con Juan José Arreola”. Quimera 1 (1980): 23-27.

Mitcham, Carl, ed. Philosophy of Technology in Spanish Speaking Countries. Dordrecht: Kluwer Academic Publishers, 1993. Philosophy and Technology 10.

Munguía Zatarain, Martha Elena. Humor, parodia, ironía. Juan José Arreola. Madrid: Ediciones del Orto, 2006.

Ortega y Gasset, José. Obras completas. 12 vols. Madrid: Revista de Occidente, 1945-47.

Phillips, Michael, ed. Philosophy and Science Fiction. Buffalo, NY: Prometheus Books, 1984.

Peña Borrero, Margarita M. "Science, Technology and Society Education in the Latin American Context." Philosophy of Technology in Spanish Speaking Countries. Carl Mitcham, ed. Dordrecht: Kluwer Academic Publishers, 1993.

Poster, Mark. "High-Tech Frankestein, or Heidegger Meets Sterlac". The Cyborg Experiments. The Extensions of the Body in the Media Age. Joanna Zylinska, ed. London: Continuum, 2002. 15-32.

Ramos, Julio. Desencuentros de la modernidad en América Latina. Literatura y política en el siglo XIX. México: Fondo de Cultura Económica, 1989.

Robinett, Jane. This Rough Magic. Technology in Latin American Fiction. New York: Peter Lang, 1994.

Rojo Solís, Juan José. “Conversaciones con Yoni Rei”. Visiones periféricas. Antología de la ciencia ficción mexicana. Sel. e introd. Miguel Ángel Fernández Delgado. México: Lumen, 2001.

Russo, John Paul. The Future Without a Past: The Humanities in a Technological Society. Columbia: U of Missouri P, 2005.

Saunders, George. "I Can Speak! TM”. In Persuasion Nation. New York: Riverhead Books, 2006. 3-11.

Schade, George. Prólogo. Confabulario and other Inventions. Juan JoséArreola. Schade, trad. Austin: U of Texas P, 1964.

Scharff, Robert C. y Val Dusek, eds. Philosophy of Technology. The Technological Condition. Malden: Blackwell, 2003.

Revista Iberoamericana, Vol. LXXVIII, Núms. 238-239,
ISSN 0034-9631 (Impreso) 
Sperber, Dan y Deirdre Wilson. Relevance. Communication and Cognition. Cambridge, Massachussets: Harvard UP, 1986.

Torres Bodet, Jaime y Bernardo Ortiz de Montellano. "Propósitos”. Las vanguardias latinoamericanas. Textos programáticos y críticos. Jorge Schwartz, ed. México: Fondo de Cultura Económica, 2002. 317-18.

Wolfe, Gary K. Critical Terms for Science Fiction and Fantasy. A Glossary and Guide to Scholarship. New York: Greenwood Press, 1986.

Vint, Sherryl. Bodies of Tomorrow. Technology, Subjectivity, Science Fiction. Toronto: U of Toronto P, 2007.

Yehya, Naief. El cuerpo transformado: Cyborgs y nuestra descendencia tecnológica en la realidad y en la ciencia ficción. México: Paidós, 2001.

Zylinska, Joanna, ed. “'The Future... Is Monstruous': Prosthetics as Ethics”. The Cyborg Experiments. The Extensions of the Body in the Media Age. London: Continuum, 2002. 214-236.

$\begin{array}{lllll}\text { ISSN 0034-9631 (Impreso) } & \text { ISSN 2154-4794 (Electrónico) }\end{array}$ 
